\title{
Capacidade de combinação por meio de análise multivariada para caracteres fenotípicos em maracujazeiro-doce
}

\author{
Maricelma Simiano Jung ${ }^{(1)}$, Eduardo Alano Vieira(2), Giovani Olegário da Silva ${ }^{(3)}$, Ademar Brancker $^{(4)}$ \\ e Rubens Onofre Nodari(5)
}

\begin{abstract}
(1)Universidade do Sul de Santa Catarina, Av. José Acácio Moreira, no 787, Caixa Postal 370, CEP 88704-900 Tubarão, SC. E-mail: msimiano@unisul.br (2)Embrapa Cerrados, BR 020, Km 18, Caixa Postal 08223, CEP 73310-970 Planaltina, DF. E-mail: vieiraea@cpac.embrapa.br (3)Embrapa Hortaliças, BR 060, Km 09, Caixa Postal 218, CEP 70359-970 Gama, DF. E-mail: olegario@cnph.embrapa.br (4)Empresa de Pesquisa Agropecuária e Extensão Rural de Santa Catarina, SC 446, Km 19, Caixa Postal 49, CEP 88840-000 Urussanga, SC. E-mail: brancher@epagri.rct-sc.br (5)Universidade Federal de Santa Catarina, Dep. de Fitotecnia, Caixa Postal 476, CEP 88040-900 Florianópolis, SC. E-mail: nodari@cca.ufsc.br
\end{abstract}

\begin{abstract}
Resumo - O objetivo deste trabalho foi estimar capacidades de combinação por meio de análise multivariada de genótipos de maracujazeiro-doce, de modo a orientar as melhores combinações para cruzamentos. Foram cruzados 12 genótipos, 6 genitores femininos e 6 genitores masculinos, na forma de dialelo parcial, e as populações segregantes foram conduzidas em blocos casualizados com quatro repetições sem a inclusão dos genitores. Os caracteres aferidos foram: peso do fruto, peso da polpa, espessura da casca, teor de sólidos solúveis totais e rendimento de polpa. Os dados obtidos foram submetidos à análise de variância, análise dialélica parcial e análise de variância multivariada dialélica. Posteriormente, foi utilizado o índice de seleção da distância ao ideótipo para seleção dos genitores. Os melhores genitores femininos foram M4 e M2 e os masculinos foram P5 e P6 e as melhores combinações de genitores são M4 x P6 e M2 x P2. Os resultados obtidos evidenciaram que a utilização conjunta da análise dialélica e análise multivariada pode ser útil a programas de melhoramento genético, em especial na orientação das melhores combinações para cruzamentos, quando o objetivo é obter ganho genético em vários caracteres simultaneamente.
\end{abstract}

Termos para indexação: Passiflora alata, análise dialélica multivariada, ideótipo, seleção de genitores, melhoramento genético.

\section{Combined ability of fruit phenotypic traits in sweet passion fruit by multivariate analysis}

\begin{abstract}
The objective of this work was to estimate the combined ability of sweet passionfruit by multivariate analysis to support breeding. Twelve genotypes, six female parents and six male parents, in a partial diallel were utilized to develop $36 \mathrm{~F}_{1}$ progenies, stablished in the field in randomized blocks with four replicates, without the parents. Weight of the fruit, weight of the pulp, epicarp thickness, total soluble solids content, and pulp production were evaluated. Data were submitted to analysis of variance, partial diallel analysis, and multivariate diallel variance analysis. Afterwards, the selection index of distance to the ideotype for selection of the parents was utilized. The better female and male parental were M4 and M2 and P5 and P6, respectively, and the better crosses were M4 x P6 and M2 x P2. The results provided evidence that the utilization of diallel and multivariate analysis at the same time can be useful to the breeding programs, in particular by guiding the selection of the best combinations for future crosses to further increase the genetic gain in various traits simultaneously.
\end{abstract}

Index terms: Passiflora alata, multivariate dialell analysis, ideotype, parental selection, plant breeding.

\section{Introdução}

Uma das fruteiras nativas do Brasil que atualmente vêm despertando interesse econômico por seu elevado valor de mercado é o maracujazeiro-doce (Passiflora alata Curtis) (Braga et al., 2005). Entretanto, para que a espécie alcance destaque ainda maior, é necessário obter cultivares com caracteres desejados pelos consumidores e produtores. Os frutos de determinada cultivar devem apresentar tamanho comercial, de 200 a $300 \mathrm{~g}$, formato piriforme ou ovalado e sem amolecimento apical, resistência mecânica (casca firme), elevada conservação em pós-colheita, elevado rendimento de polpa (superior a $30 \%$ ), elevado teor de sólidos solúveis 
totais e sabor doce acidulado. A cultivar deve, ainda, expressar elevada produtividade de frutos, precocidade, resistência a pragas e doenças entre outros caracteres (Junqueira et al., 2005).

O melhoramento genético possibilita a geração de cultivares de maracujazeiro-doce com caracteres superiores. Neste caso, o desafio do melhorista é reunir em uma só constituição genética, o maior número possível de caracteres favoráveis. Entretanto, para que um programa de melhoramento genético tenha êxito, com economia de recursos e tempo, é necessário que os cruzamentos sejam efetuados entre genitores com elevada capacidade de combinação (Allard, 1999). Dessa forma, o melhorista concentrará seus esforços em populações segregantes com elevada frequiência de indivíduos transgressivos, especialmente nos caracteres relacionados à produtividade, qualidade e resistência a pragas e doenças.

Entre os métodos de escolha de genitores, um dos mais eficientes e comumente utilizados em programas de melhoramento genético é a análise dialélica, que determina o potencial dos genitores em combinações híbridas, a ação gênica que controla os caracteres, a herança dos caracteres e a existência de heterose, e proporciona avanços para a seleção (Jaramillo et al., 2005). Existem vários métodos usados na análise de cruzamentos dialélicos, sendo que o método proposto por Griffing (1956) é um dos mais empregados. Esse método gera informações a respeito da capacidade geral de combinação dos genitores (CGC), função da concentração de genes predominantemente aditivos, e da capacidade específica de combinação (CEC), decorrente da concentração de genes basicamente de efeito não aditivo (Castiglioni et al., 1999). Essa análise, embora amplamente utilizada, tem como desvantagem o trabalho envolvido na obtenção dos híbridos e nas avaliações (Fuzatto et al., 2002) bem como no fato de ser uma análise univariada (Ledo et al., 2003).

$\mathrm{Na}$ seleção de genótipos superiores em populações segregantes, o melhorista necessita considerar vários caracteres conjuntamente. Contudo, a maioria das técnicas biométricas aplicadas a cruzamentos dialélicos são univariadas e as análises combinadas praticamente restringem-se a procedimentos bivariados. A análise dos caracteres isoladamente pode não ser suficiente, pois não considera as correlações existentes entre eles. É importante ressaltar, no entanto, que essas análises vêm gerando um grande volume de informações para programas de melhoramento genético de diversas espécies (Barbosa \& Pinto, 1998; Jaramillo et al., 2005; Lorencetti et al., 2006; Rodrigues et al., 2006).
Existe a alternativa da utilização da análise multivariada em cruzamentos dialélicos, que permite combinar as múltiplas informações obtidas na unidade experimental, o que facilita a seleção e possibilita a discriminação das populações mais promissoras, principalmente no contexto da seleção de genitores para melhoramento genético (Ledo et al., 2003). Essa estratégia é extremamente relevante no melhoramento genético do maracujazeiro-doce, principalmente para uma nova região de cultivo, uma vez que permite a seleção de genitores com elevada capacidade de combinação para várias características simultaneamente, diminuindo consideravelmente o tempo decorrido para o lançamento de cultivares superiores para vários caracteres de importância agronômica.

O objetivo deste trabalho foi estimar as capacidades de combinação uni e multivariada de genótipos de maracujazeiro-doce de modo a orientar as melhores combinações para cruzamentos.

\section{Material e Métodos}

O experimento foi conduzido na estação experimental da Epagri, situada a $28^{\circ} 31^{\prime} \mathrm{S}$ e $49^{\circ} 19^{\prime} \mathrm{O}$, a altitude de $48 \mathrm{~m}$, no Município de Urussanga, SC. Os genótipos empregados na análise dialélica foram obtidos em uma coleção de 1.250 genótipos meios-irmãos de Passiflora alata Curtis pertencentes a Epagri, oriundos da hibridação de 25 genitores femininos com um genitor masculino. Nessa população, foram selecionados 12 genótipos fenotipicamente contrastantes para os caracteres rendimento de polpa, peso médio do fruto e espessura da casca (Jung, 2003). Seis genótipos como fêmeas (M1 a M6) e seis como machos (P1 a P6) foram selecionados e cruzados (polinização manual) na forma de um dialelo parcial, totalizando 36 cruzamentos. Para garantir a efetividade dos cruzamentos, as flores foram cobertas antes da antese e emasculadas antes da polinização.

As sementes $F_{1}$ foram postas para germinar em casa de vegetação e, posteriormente, as mudas foram transplantadas para o campo. Duas mudas foram plantadas em cada cova e, após total estabelecimento, foi mantida uma planta por cova, tendo restado 576 plantas $F_{1}$ segregantes.

O experimento foi conduzido na forma de blocos completos casualizados com quatro repetições, sendo cada parcela composta por quatro plantas. Nas parcelas experimentais, as plantas foram mantidas no espaçamento de $1 \mathrm{~m}$ entre plantas e 2,5 m entre linhas e conduzidas no sistema de espaldeira. Cada bloco foi composto por 36 tratamentos, sem a inclusão dos genitores, os quais não necessariamente precisam ser incluídos para se efetuar inferências pertinentes 
à capacidade de combinação dos genitores estudados (Tai \& De Jong, 1991), em especial nesse caso, em que os $\mathrm{F}_{1}$ foram multiplicados por sementes e os pais teriam de ser multiplicados por estaquia. Os caracteres aferidos por meio da avaliação de dez frutos por planta foram peso do fruto em gramas, peso da polpa em gramas, espessura da casca em $\mathrm{mm}$, teor de sólidos solúveis totais em ${ }^{\circ}$ Brix e rendimento de polpa por meio da razão entre o peso da polpa e o peso total do fruto.

Os dados coletados foram submetidos às análises de variância e dialélica parcial, sem a inclusão dos genitores, pelo programa Genes (Cruz, 2001). Na análise de variância multivariada dialélica, foram utilizadas as médias ajustadas das tabelas dialélicas e as informações da análise de variância univariada preliminar, com o modelo 4 proposto por Griffing (1956), de acordo com método descrito por Ledo (2002). A hipótese de igualdade dos efeitos genéticos da análise dialélica multivariada foi examinada pelo teste de Wilks (1932), por meio da aproximação de F (Harris, 1975).

Com base nos resultados obtidos na análise dialélica parcial, foram definidos três ideótipos ideais arbitrários. O primeiro e o segundo ideótipos, relativos aos genitores femininos e masculinos, respectivamente, foram definidos por meio das maiores capacidades gerais de combinação e médias entre os genitores estudados para todos os caracteres aferidos, exceto espessura da casca em que foram considerados os menores valores; o terceiro ideótipo foi definido a partir das maiores capacidades específicas de combinações e médias entre os cruzamentos estudados para todos os caracteres aferidos, com exceção da espessura da casca, em que foram considerados os menores valores. Posteriormente, efetuou-se a análise multivariada, por meio do cálculo da distância euclidiana entre os genitores femininos, genitores masculinos, cruzamentos $\mathrm{F}_{1}$ e seus respectivos ideótipos. Dessa forma, os genitores e cruzamentos foram classificados de acordo com a distância que apresentaram em relação ao ideótipo, ou seja, de acordo com o índice de seleção da distância ao ideótipo. Essa estratégia permite a identificação dos melhores genitores femininos, genitores masculinos e cruzamentos como sendo os que apresentaram as menores distâncias em relação aos seus respectivos ideótipos.

\section{Resultados e Discussão}

A análise de variância e as estimativas das capacidades gerais e específicas de combinação não revelaram diferenças significativas a $5 \%$ de probabilidade, entre os cruzamentos avaliados, para nenhum dos caracteres aferidos (Tabela 1). Esses resultados podem ser explicados pelo fato de os genitores serem meios-irmãos, e as amplitudes em torno das médias não terem sido elevadas. Resultados semelhantes foram reportados por Junqueira et al. (2005) que, ao avaliar dez progênies de diferentes procedências de maracujazeiro-doce, não detectaram diferenças estatisticamente significativas entre as progênies quanto aos caracteres espessura da casca, peso da polpa e rendimento da polpa, entretanto detectaram diferenças quanto aos caracteres peso de fruto e teor de sólidos solúveis totais. Por sua vez Martins et al. (2003), ao avaliar cinco populações de maracujazeiro-doce, não detectaram diferenças significativas entre as populações quanto aos caracteres teor de sólidos solúveis totais, espessura da casca e rendimento de polpa, e detectaram diferenças quanto aos caracteres peso de fruto e peso da polpa. É possível constatar, portanto, que é preciso incorporar genitores divergentes em futuros programas de melhoramento genético de maracujazeiro-doce,

Tabela 1. Análise de variância univariada de 36 híbridos $\mathrm{F}_{1}$ e análise conjunta de variância para capacidade geral de combinação (CGC) e capacidade específica de combinação (CEC) dos caracteres peso do fruto (PF), peso da polpa (PP), espessura da casca (EC), teor de sólidos solúveis totais (TSST) e rendimento de polpa (RP), em maracujazeiro-doce.

\begin{tabular}{|c|c|c|c|c|c|c|}
\hline \multirow[t]{2}{*}{ Fonte de variação } & \multirow[t]{2}{*}{ GL } & \multicolumn{5}{|c|}{ Caracteres } \\
\hline & & $\mathrm{PF}(\mathrm{g})$ & $\mathrm{PP}(\mathrm{g})$ & $\mathrm{EC}(\mathrm{mm})$ & TSST $\left({ }^{\circ}\right.$ Brix $)$ & $\mathrm{RP}(\%)$ \\
\hline $\mathrm{QM}^{(1)}$ Tratamentos & 35 & 396,93 & 52,48 & 0,91 & 2,50 & 11,10 \\
\hline QM Resíduo & 105 & 587,60 & 63,21 & 1,14 & 2,63 & 10,39 \\
\hline QM Grupos & 35 & 163,90 & 21,82 & 0,57 & 0,27 & 2,58 \\
\hline QM CGC (mães) & 5 & 188,60 & 17,50 & 0,36 & 0,43 & 3,50 \\
\hline QM CGC (pais) & 5 & 175,14 & 21,56 & 0,28 & 0,15 & 0,15 \\
\hline QM CEC & 25 & 156,71 & 22,74 & 0,67 & 0,27 & 2,88 \\
\hline Coeficiente de variação (\%) & & 11,41 & 12,15 & 11,49 & 9,03 & 10,49 \\
\hline Média & & 213,91 & 65,90 & 9,36 & 18,06 & 1,78 \\
\hline Amplitude máxima & & 166,18 & 46,50 & 7,83 & 16,56 & 22,53 \\
\hline Amplitude mínima & & 262,60 & 80,58 & 11,23 & 21,78 & 35,07 \\
\hline
\end{tabular}

${ }^{(1)}$ Quadrado médio. 
visando à ampliação da variabilidade genética, que é imprescindível no processo de seleção. Essa incorporação de variabilidade não será difícil, em razão de a fruteira ser nativa do Brasil e expressar elevada diversidade genética (Aukar et al., 2002; Melletti et al., 2003).

A análise de variância multivariada do modelo de Griffing (1956) revelou efeitos significativos para CEC e CGC, nos dois grupos de genitores (Tabela 2). Dessa forma, é necessário considerar a CEC e CGC para vários caracteres simultaneamente, a fim de melhorá-los concomitantemente. Para tanto, há a possibilidade da utilização de procedimentos multivariados, como a estimativa da distância entre os genitores e cruzamentos e seus ideótipos, que vise à seleção dos melhores genitores e cruzamentos, na obtenção de avanços genéticos uniformes de todos os caracteres avaliados.

Quanto aos genitores femininos, as maiores distâncias em relação ao ideótipo foram detectadas em M1 e M3, o que indica que esses genótipos contribuíram pouco para a elevação da média dos caracteres em consideração. Os genitores que mais se aproximaram do ideótipo foram
M4 e M2, o que indica que esses genótipos foram os que mais contribuíram para a elevação da média dos cruzamentos. Em virtude de terem se destacado em relação à CGC, que indica predominância de controle genético aditivo (Gaur et al., 1983; Ramalho et al., 1993), M4 e M2 devem ser priorizados em futuros cruzamentos, objetivando ganho genético (progênies superiores) no conjunto de caracteres considerados (Barbosa \& Pinto, 1998; Lorencetti et al., 2006; Rodrigues et al., 2006) (Tabela 3).

Em relação aos genitores masculinos, as maiores distâncias do ideótipo foram obtidas pelos genótipos P4, P2, P1 e P3. Esses genótipos devem ser evitados na constituição de novos blocos de cruzamentos. Já os genitores P5 e P6 foram os que mais se aproximaram do ideótipo (Tabela 3). Dessa forma, sua utilização como genitores em cruzamentos futuros poderá acarretar ganhos consideráveis no melhoramento genético do maracujazeirodoce, principalmente em razão da predominância de controle genético aditivo na manifestação dos caracteres avaliados (Barbosa \& Pinto, 1998; Lorencetti et al., 2006; Rodrigues et al., 2006).

Tabela 2. Esquema da análise de variância multivariada utilizada na análise dos caracteres avaliados no maracujazeiro-doce ${ }^{(1)}$.

\begin{tabular}{|c|c|c|c|c|c|c|c|}
\hline Fonte de variação & GL & Matriz da SQP & $\Lambda$ & $\mathrm{F}$ & V1 & V2 & $\mathrm{P}>\mathrm{F}$ \\
\hline$\overline{\mathrm{CGC}}$ & 5 & SQP (CGC) & 0,0001 & 157,47 & 25 & 377 & 0,0000 \\
\hline CGC & 5 & SQP (CGC) & 0,0001 & 187,77 & 25 & 377 & 0,0000 \\
\hline CEC & 25 & SQP (CEC) & 0,0001 & 399,42 & 125 & 502 & 0,0000 \\
\hline Resíduo & 105 & SQP (Resíduo) & & & & & \\
\hline
\end{tabular}

${ }^{(1)}$ CGC: capacidade geral de combinação; CEC: capacidade específica de combinação; SQP: soma dos quadrados dos produtos; $\Lambda$ : lambda do teste de Wilks (1932); F: aproximação F do teste de Haris (1975); V1: número de variáveis x graus de liberdade da CGC; V2: número de variáveis x graus de liberdade da CEC; P>F: probabilidade de significância para o valor de F.

Tabela 3. Estimativa dos efeitos da CGC, média dos cruzamentos dos seis genitores feminino (M1 a M6) e seis masculinos (P1 a P6), ideótipos dos genitores femininos e masculinos e distância entre genitores e ideótipos dos caracteres peso do fruto (PF), peso da polpa (PP), espessura da casca (EC), teor de sólidos solúveis totais (TSST) e rendimento de polpa (RP), em maracujazeiro-doce.

\begin{tabular}{|c|c|c|c|c|c|c|c|c|c|c|c|}
\hline \multirow[t]{2}{*}{ Genitores } & \multicolumn{2}{|c|}{$\mathrm{PF}(\mathrm{g})$} & \multicolumn{2}{|c|}{$\mathrm{PP}(\mathrm{g})$} & \multicolumn{2}{|c|}{$\mathrm{EC}(\mathrm{mm})$} & \multicolumn{2}{|c|}{ TSST ( ${ }^{\circ}$ Brix) } & \multicolumn{2}{|c|}{ RP $(\%)$} & \multirow{2}{*}{$\begin{array}{l}\text { Distância } \\
\text { ao ideótipo }\end{array}$} \\
\hline & $\mathrm{CGC}$ & Média & CGC & Média & $\overline{\mathrm{CGC}}$ & Média & CGC & Média & $\mathrm{CGC}$ & Média & \\
\hline \multicolumn{12}{|l|}{ Femininos } \\
\hline M1 & $-0,26$ & 213,65 & $-1,01$ & 64,89 & 0,19 & 9,55 & $-0,14$ & 17,92 & $-0,45$ & 30,48 & 7,16 \\
\hline M2 & $-2,22$ & 211,68 & 0,25 & 66,15 & $-0,001$ & 9,36 & 0,13 & 18,19 & 0,52 & 31,45 & 3,76 \\
\hline M3 & $-1,45$ & 212,46 & $-0,63$ & 65,27 & $-0,07$ & 9,29 & $-0,15$ & 17,92 & $-0,12$ & 30,81 & 5,47 \\
\hline M4 & 2,60 & 216,51 & 1,30 & 67,20 & 0,07 & 9,43 & 0,06 & 18,13 & 0,21 & 31,15 & 3,25 \\
\hline M5 & $-2,83$ & 211,07 & $-0,44$ & 65,46 & $-0,17$ & 9,18 & 0,16 & 18,22 & 0,22 & 31,15 & 4,12 \\
\hline M6 & 4,16 & 218,07 & 0,53 & 66,43 & $-0,01$ & 9,35 & $-0,05$ & 18,01 & $-0,38$ & 30,55 & 4,34 \\
\hline Ideótipo feminino & 4,16 & 218,07 & 1,30 & 66,43 & $-0,17$ & 9,18 & 0,16 & 18,22 & 0,52 & 31,45 & 0 \\
\hline \multicolumn{12}{|l|}{ Masculinos } \\
\hline $\mathrm{P} 1$ & 0,97 & 214,88 & 0,40 & 66,31 & 0,13 & 9,49 & $-0,11$ & 17,95 & 0,07 & 31,01 & 5,54 \\
\hline $\mathrm{P} 2$ & $-2,42$ & 211,49 & $-0,68$ & 65,22 & 0,11 & 9,47 & 0,09 & 18,16 & 0,01 & 30,94 & 5,63 \\
\hline P3 & $-3,16$ & 210,74 & $-1,09$ & 64,81 & $-0,02$ & 9,34 & 0,06 & 18,12 & 0,04 & 30,97 & 5,40 \\
\hline $\mathrm{P} 4$ & 0,21 & 214,12 & $-0,35$ & 65,55 & $-0,14$ & 9,22 & $-0,06$ & 18,01 & $-0,15$ & 30,78 & 5,95 \\
\hline P5 & 4,43 & 218,34 & 1,59 & 67,50 & $-0,08$ & 9,27 & 0,04 & 18,11 & 0,01 & 30,94 & 1,66 \\
\hline P6 & $-0,03$ & 213,88 & 0,11 & 66,01 & $-0,004$ & 9,35 & $-0,02$ & 18,04 & 0,02 & 30,95 & 4,08 \\
\hline Ideótipo masculino & 4,43 & 218,34 & 1,59 & 67,50 & $-0,14$ & 9,22 & 0,09 & 18,16 & 0,07 & 31,01 & 0 \\
\hline
\end{tabular}


Em relação às capacidades específicas de combinação e às médias das combinações, as maiores distâncias em relação à combinação ideal de caracteres (ideótipo) foram reveladas pelos cruzamentos M3 x P3, M1 x P3, M2 x P1 e M4 x P2, o que revela que essas combinações de genótipos foram muito inferiores à combinação ideal, e, portanto oferecem pouca oportunidade de seleção de genótipos superiores. As combinações que mais se aproximaram da ideal foram M2 x P2, M3 x P4 e M4 x P6, o que indica que essas combinações foram superiores às demais e, portanto, permitiram a seleção de genótipos superiores.

A CEC, que gera informações dos genes de efeito basicamente não aditivo (dominância e epistasia) (Castiglioni et al., 1999), é importante na seleção dos cruzamentos específicos a serem efetuados, em especial em maracujazeiro-doce, cujos genótipos superiores podem ser multiplicados vegetativamente, mantendo um possível arranjo gênico favorável. Entretanto, é relevante ressaltar que os genitores utilizados na obtenção das progênies estudadas são meios-irmãos e, dessa forma, exibem coeficiente de endogamia superior ao exibido por genitores não aparentados, fato que pode ter contribuído para os efeitos reduzidos da dominância nos cruzamentos estudados (Allard, 1999).

A combinação M2 x P2, mesmo envolvendo o genitor P2, que se distanciou bastante do ideótipo, pode ser sugerida para o melhoramento genético, uma vez que o genitor M2 revelou pequena distância de seu ideótipo (Tabela 3), e a combinação foi a que mais se aproximou do ideótipo para CEC (Tabela 4). A combinação M3 x P4 foi a terceira que mais se

Tabela 4. Efeitos da capacidade específica de combinação (CEC) e médias ( $\mu$ ) em 36 cruzamentos de maracujazeiro-doce e ideótipo e distância entre os cruzamentos e o ideótipo, para os caracteres peso do fruto (PF), peso da polpa (PP), espessura da casca (EC), teor de sólidos solúveis totais (TSST) e rendimento de polpa (RP).

\begin{tabular}{|c|c|c|c|c|c|c|c|c|c|c|c|}
\hline \multirow[t]{2}{*}{ Cruzamento $^{(1)}$} & \multicolumn{2}{|c|}{$\begin{array}{l}\text { PF } \\
(\mathrm{g})\end{array}$} & \multicolumn{2}{|c|}{$\begin{array}{l}\text { PP } \\
(\mathrm{g})\end{array}$} & \multicolumn{2}{|c|}{$\begin{array}{c}\mathrm{EC} \\
(\mathrm{mm})\end{array}$} & \multicolumn{2}{|c|}{$\begin{array}{c}\text { TSST } \\
\left({ }^{\circ} \text { Brix }\right)\end{array}$} & \multicolumn{2}{|c|}{$\begin{array}{l}\mathrm{RP} \\
(\%)\end{array}$} & \multirow[t]{2}{*}{$\begin{array}{c}\text { Distância ao } \\
\text { ideótipo }\end{array}$} \\
\hline & CEC & $\mu$ & CEC & $\mu$ & CEC & $\mu$ & $\mathrm{CEC}$ & $\mu$ & CEC & $\mu$ & \\
\hline $1 \times 1$ & $-1,23$ & 213,39 & 0,76 & 66,05 & $-0,39$ & 9,29 & 0,21 & 18,02 & 0,45 & 31,01 & 6,26 \\
\hline $1 \times 2$ & 6,33 & 217,56 & 2,88 & 67,09 & $-0,24$ & 9,42 & $-0,17$ & 17,84 & 0,42 & 30,91 & 6,64 \\
\hline $1 \times 3$ & $-6,78$ & 203,70 & $-2,25$ & 61,55 & $-0,06$ & 9,47 & $-0,23$ & 17,75 & $-0,06$ & 30,46 & 9,80 \\
\hline $1 \times 4$ & 1,45 & 215,31 & $-0,08$ & 64,46 & 0,02 & 9,43 & 0,08 & 17,94 & $-0,14$ & 30,19 & 7,53 \\
\hline $1 \times 5$ & $-0,70$ & 217,38 & $-1,77$ & 64,72 & 0,12 & 9,58 & 0,00 & 17,96 & $-0,68$ & 29,81 & 8,47 \\
\hline $1 \times 6$ & 0,93 & 214,54 & 0,46 & 65,46 & 0,55 & 10,09 & 0,11 & 18,01 & 0,01 & 30,50 & 8,14 \\
\hline $2 \times 1$ & $-6,83$ & 205,83 & $-3,23$ & 63,33 & $-0,35$ & 9,14 & $-0,36$ & 17,72 & $-0,59$ & 30,94 & 9,69 \\
\hline $2 \times 2$ & 3,99 & 213,25 & 1,24 & 66,71 & $-0,01$ & 9,46 & 0,68 & 18,97 & 0,02 & 31,48 & 4,95 \\
\hline $2 \times 3$ & 1,94 & 210,46 & 0,91 & 65,98 & $-0,09$ & 9,25 & $-0,37$ & 17,88 & 0,28 & 31,77 & 7,49 \\
\hline $2 \times 4$ & $-8,14$ & 203,76 & $-1,51$ & 64,29 & $-0,17$ & 9,05 & $-0,02$ & 18,11 & 0,31 & 31,61 & 7,91 \\
\hline $2 \times 5$ & 7,18 & 223,29 & 2,91 & 70,66 & 0,84 & 10,11 & $-0,02$ & 18,21 & 0,42 & 31,88 & 7,06 \\
\hline $2 \times 6$ & 1,86 & 213,51 & $-0,32$ & 65,94 & $-0,22$ & 9,13 & 0,09 & 18,26 & $-0,44$ & 31,02 & 6,46 \\
\hline $3 \times 1$ & 7,03 & 220,46 & 0,23 & 65,91 & 0,54 & 9,96 & 0,19 & 17,99 & $-0,86$ & 30,02 & 8,19 \\
\hline $3 \times 2$ & $-2,04$ & 208,00 & $-1,55$ & 63,04 & $-0,45$ & 8,95 & $-0,06$ & 17,95 & $-0,41$ & 30,41 & 8,26 \\
\hline $3 \times 3$ & 2,32 & 211,61 & $-2,93$ & 61,26 & $-0,38$ & 8,89 & $-0,16$ & 17,81 & $-1,73$ & 29,12 & 10.07 \\
\hline $3 \times 4$ & 7,14 & 219,81 & 4,38 & 69,31 & $-0,04$ & 9,11 & $-0,05$ & 17,81 & 1,06 & 31,72 & 5,62 \\
\hline $3 \times 5$ & $-1,55$ & 215,34 & 0,16 & 67,03 & $-0,18$ & 9,02 & 0,05 & 18,01 & 0,19 & 31,01 & 6,46 \\
\hline $3 \times 6$ & $-12,90$ & 199,52 & $-0,30$ & 65,09 & 0,52 & 9,80 & 0,03 & 17,92 & 1,74 & 32,56 & 9,11 \\
\hline $4 \times 1$ & $-1,25$ & 216,24 & 0,58 & 68,19 & 0,45 & 10,01 & 0,13 & 18,14 & 0,41 & 31,63 & 7,04 \\
\hline $4 \times 2$ & $-7,40$ & 206,69 & $-3,33$ & 63,19 & 0,17 & 9,71 & $-0,21$ & 18,01 & $-0,56$ & 30,60 & 9,69 \\
\hline $4 \times 3$ & 10,78 & 224,13 & 4,61 & 70,72 & 0,55 & 9,95 & $-0,07$ & 18,12 & 0,57 & 31,76 & 6,51 \\
\hline $4 \times 4$ & $-5,23$ & 211,50 & $-2,24$ & 64,61 & $-0,37$ & 8,92 & 0,00 & 18,07 & $-0,31$ & 30,69 & 7,79 \\
\hline $4 \times 5$ & $-2,40$ & 218,54 & $-0,69$ & 68,11 & $-0,23$ & 9,11 & 0,14 & 18,31 & 0,05 & 31,21 & 5,88 \\
\hline $4 \times 6$ & 5,50 & 221,98 & 1,07 & 68,38 & $-0,57$ & 8,85 & 0,01 & 18,11 & $-0,16$ & 31,00 & 5,61 \\
\hline $5 \times 1$ & 4,91 & 216,96 & 1,96 & 67,82 & $-0,05$ & 9,27 & $-0,14$ & 17,97 & 0,20 & 31,43 & 6,30 \\
\hline $5 \times 2$ & $-3,09$ & 205,56 & 2,33 & 67,10 & 0,31 & 9,61 & $-0,06$ & 18,26 & 1,55 & 32,72 & 6,82 \\
\hline $5 \times 3$ & $-3,41$ & 204,50 & 0,07 & 64,44 & 0,18 & 9,34 & 0,62 & 18,90 & 0,57 & 31,76 & 6,31 \\
\hline $5 \times 4$ & $-3,00$ & 208,28 & $-3,18$ & 61,93 & 0,05 & 9,09 & 0,08 & 18,24 & $-1,00$ & 30,00 & 8,92 \\
\hline $5 \times 5$ & $-1,03$ & 214,47 & 0,15 & 67,20 & $-0,45$ & 8,65 & $-0,26$ & 18,00 & 0,10 & 31,26 & 6,89 \\
\hline $5 \times 6$ & 5,62 & 216,66 & $-1,33$ & 64,24 & $-0,04$ & 9,14 & $-0,24$ & 17,96 & $-1,42$ & 29,75 & 8,77 \\
\hline $6 \times 1$ & $-2,64$ & 216,41 & $-0,30$ & 66,53 & $-0,19$ & 9,29 & $-0,03$ & 17,87 & 0,38 & 31,01 & 7,04 \\
\hline $6 \times 2$ & 2,22 & 217,87 & $-1,57$ & 64,18 & 0,22 & 9,68 & $-0,19$ & 17,92 & $-1,02$ & 29,54 & 9,17 \\
\hline $6 \times 3$ & $-4,86$ & 210,05 & $-0,41$ & 64,93 & $-0,21$ & 9,12 & 0,21 & 18,28 & 0,37 & 30,96 & 6,65 \\
\hline $6 \times 4$ & 7,78 & 226,06 & 2,63 & 68,71 & 0,50 & 9,71 & $-0,09$ & 17,87 & 0,07 & 30,47 & 7,34 \\
\hline $6 \times 5$ & $-1,50$ & 221,00 & $-0,77$ & 67,26 & $-0,09$ & 9,17 & 0,09 & 18,15 & $-0,08$ & 30,48 & 6,61 \\
\hline $6 \times 6$ & $-1,00$ & 217,04 & 0,42 & 66,96 & $-0,23$ & 9,11 & 0,00 & 17,99 & 0,28 & 30,84 & 6,50 \\
\hline Ideótipo & 10,78 & 226,06 & 4,61 & 70,72 & $-0,57$ & 8,65 & 0,68 & 18,97 & 1,74 & 32,72 & 0 \\
\hline
\end{tabular}

${ }^{(1)}$ Genitor feminino x genitor masculino. 
aproximou do ideótipo; entretanto, seus genitores evidenciaram elevada distância dos respectivos ideótipos (Tabela 3), o que pode ser um indicativo de que tal combinação não deve ser prioritariamente selecionada. A combinação mais indicada para a melhoria conjunta dos caracteres considerados foi M4 x P6, pois os dois genitores revelaram reduzidas distâncias em relação ao ideótipo (Tabela 3), em particular M4, que evidenciou a menor distância ao ideótipo. Dessa forma, as combinações específicas M3 x P4 e M4 x P6 devem ser priorizadas futuramente por envolverem pelo menos um dos genitores com elevada CGC e também elevada CEC para o conjunto de caracteres avaliados.

\section{Conclusão}

A utilização conjunta das análises dialélica e multivariada é útil na escolha das melhores combinações de genitores, com vistas ao ganho genético em vários caracteres simultaneamente.

\section{Agradecimentos}

À Unisul, pelo apoio à primeira autora; à Epagri, pelo material vegetal e por ceder o campo experimental para condução do experimento; ao CNPq, pela bolsa concedida a Rubens Onofre Nodari.

\section{Referências}

ALLARD, R.W. Principies of plant breeding. $2^{\text {nd }}$ ed. New York: J. Wiley, 1999. 254p.

AUKAR, A.P.; LEMOS, E.G.M.; OLIVEIRA, J.C. Genetic variations among passion fruit species using RAPD markers. Revista Brasileira de Fruticultura, v.24, p.738-740, 2002.

BARBOSA, M.H.P.; PINTO, C.A.B.P. Análise dialélica parcial entre cultivares de batatas nacionais e introduzidas. Pesquisa Agropecuária Brasileira, v.33, p.307-320, 1998.

BRAGA, M.F.; JUNQUEIRA, N.T.V.; FALEIRO, F.G.; BELLON, G.; JUNQUEIRA, K.P. Maracujá-doce: melhoramento genético e germoplasma. In: FALEIRO, F.G.; JUNQUEIRA, N.T.V.; BRAGA, M.F. (Ed.). Maracujá: germoplasma e melhoramento genético. Planaltina: Embrapa Cerrados, 2005. p.601-616.

CASTIGLIONI, V.B.R.; OLIVEIRA, M.F. de; ARIAS, C.A.A. Análise da capacidade combinatória entre linhagens de girassol. Pesquisa Agropecuária Brasileira, v.34, p.981-988, 1999.

CRUZ, C.D. Programa Genes: aplicativo computacional em genética e estatística. Viçosa: Ed. da UFV, 2001. 648p.

FUZATTO, S.R.; FERREIRA, D.F.; RAMALHO, M.A.P.; RIBEIRO, P.H.E. Divergência genética e sua relação com os cruzamentos dialélicos na cultura do milho. Ciência e Agrotecnologia, v.26, p.22-32, 2002.

GAUR, P.C.; GOPAL, J.; RANA, M.S. Combining ability for yield, its components and tuber dry matter in potato. Indian Journal of Agricultural Sciences, v.53, p.876-879, 1983.

GRIFFING, B. Concept of general and specific combining ability in relation to diallel crossing systems. Australian Journal of Biological Sciences, v.9, p.463-493, 1956.

HARRIS, R.J. A primer of multivariate statistics. New York: Academic Press, 1975. 332p.

JARAMILLO, G.; MORANTE, N.; PÉREZ, J.C.; CALLE, F.; CEBALLOS, H.; ARIAS, B.; BELLOTTI, A.C. Diallel analysis in cassava adapted to the midaltitude valleys environment. Crop Science, v.45, p.1058-1063, 2005.

JUNG, M.S. Análise da base genética do rendimento de polpa e resistência da casca do maracujazeiro-doce (Passiflora alata) e seleção de progênies superiores. 2003. 98p. Dissertação (Mestrado) - Universidade Federal de Santa Catarina, Florianópolis.

JUNQUEIRA, N.T.V.; PEIXOTO, J.R.; BRANCHER, A.; JUNQUEIRA, K.P.; FIALHO, J.F. Melhoramento genético do maracujá-doce. In: MANICA, I.; BRANCHER, A.; SANZONOWICZ, C.; ICUMA, I.M.; AGUIAR, J.L.P.; AZEVEDO, J.A.; VASCONCELLOS, M.A.S.; JUNQUEIRA, N.T.V. (Org.). Maracujá-doce: tecnologia de produção, pós-colheita, mercado. Porto Alegre: Cinco Continentes, 2005. p.39-46.

LEDO, C.A.S. Análises de variância multivariada para os cruzamentos dialélicos. 2002. 126p. Tese (Doutorado) Universidade Federal de Lavras, Lavras.

LEDO, C.A.S.; FERREIRA, D.F.; RAMALHO, M.A.P. Análise de variância multivariada para os cruzamentos dialélicos. Ciência e Agrotecnologia, v.27, p.1214-1221, 2003.

LORENCETTI, C.; CARVALHO, F.I.F.; OLIVEIRA, A.C.; VALÉRIO, I.P.; HARTWIG, I.; MARCHIORO, V.S.; VIEIRA, E.A. Retrocruzamento como uma estratégia de identificar genótipos e desenvolver populações segregantes promissoras em aveia. Ciência Rural, v.36, p.1118-1125, 2006.

MARTINS, M.R.; OLIVEIRA, J.C.; MAURO, A.O.; SILVA, P.C. Avaliação de populações de maracujazeiro-doce (Passiflora alata Curtis) obtidas de polinização aberta. Revista Brasileira de Fruticultura, v.25, p.111-114, 2003.

MELETTI, L.M.M.; BERNACCI, L.C.; SOARES-SCOTT, M.D.; AZEVEDO FILHO, A.; MARTINS, A.L.M. Variabilidade genética em caracteres morfológicos, agronômicos e citogenéticos de populações de maracujazeiro-doce (Passiflora alata Curtis). Revista Brasileira de Fruticultura, v.25, p.275-278, 2003.

RAMALHO, M.A.P.; SANTOS, J.B. dos; ZIMMERMANN, M.J.O. Genética quantitativa em plantas autógamas: aplicações no melhoramento do feijoeiro. Goiânia: UFV, 1993. 271p.

RODRIGUES, M.C.; CHAVES, L.J.; PACHECO, C.A.P. Heterosis in crosses among white grain maize populations with high quality protein. Pesquisa Agropecuária Brasileira, v.41, p.59-66, 2006.

TAI, G.C.C.; DE JONG, H. Evaluation of potato hybrids obtained from tetraploid-diploid crosses. Plant Breeding, v.107, p.183-189, 1991.

WILKS, S.S. Certain generalizations in the analysis of variance. Biometrika, v.24, p.471-494, 1932. 